\title{
Research on energy management four wheel drive robot assisted
}

\author{
YinBo Du ${ }^{1, a}$, Pengju Si ${ }^{2,3, b}$, Lei Xia ${ }^{1, a}$, Da-Hong Wang ${ }^{3, c}$, Xian Meng ${ }^{1, a}$ \\ ${ }^{1}$ State Grid Chongqing Electric Power Company (Co.) Electric Power Research Institute, Chongqing, \\ 401123, China; \\ ${ }^{2}$ Henan Polytechnic University, Jiaozuo 454000, China; \\ ${ }^{3}$ Shenzhen Institute of Advanced Smart Technology, \\ Shenzhen, 518000, China; \\ a1341775116@qq.com, b970349923@qq.com, ‘65168213@qq.com
}

\begin{abstract}
Keywords: four wheel independent drive, electric vehicle battery, auxiliary robot, energy management.
\end{abstract}

\begin{abstract}
In recent years, the field of electric vehicles is the first application of the new energy industrial technology platform, with the continuous progress of human science and technology, the future car development is the inevitable direction of electric drive electric vehicle. However, wheel independent drive electric unmanned ground platform is pure electric vehicle technology as the carrier, the use of unmanned technology for the development of robot assisted driving oriented industry needs a new four wheel independent. Today, for the pure electric vehicles, vehicle energy management technology is always one of the key technologies in the development of control due to the car battery in the storage can, there exist some defects in the aspects of the use of life, which restricted the further development and industrialization of electric vehicle. How to correct and reasonable use of electric vehicle battery limited energy is an urgent problem. This paper introduces a technical route for energy management driven robot assisted four wheel independent and development prospects.
\end{abstract}

\section{Introduction}

Electric vehicle energy management is under the premise of ensuring the vehicle performance, maximize the use of vehicle battery energy reserves. Energy management can be defined as through pre designed some advanced control algorithm decision power release power size, or how to allocate the power between the power source and the vehicle energy management need to achieve the goal of a lot of, traditional vehicle to continuously improve vehicle dynamic performance and stability, also as far as possible to improve fuel economy, reduce pollution emissions; for pure electric robot, prolong vehicle powered by the power of life is not to be ignored in the problem.[1,2] The vehicle energy management as the core functions of the vehicle management system generally includes the following:

1) distribution of vehicle energy, optimize the performance of the system;

2)SOC real-time monitoring of the battery energy storage device, the remaining power, the vehicle driving energy and electricity.Preparation of electricity;

3) monitoring and protection of energy storage device, recording the work history, prolonging the service life.

4) with regenerative braking energy recovery function, and effective combination of vehicle safety performance;

\section{The Main Function Of Vehicle Battery Energy Management System}

Onboard battery energy management system is a strong guarantee for robot assisted battery, battery, commonly known as the "protection of God" by of battery and effective management measures, a strong guarantee for robot assisted battery performance, improve efficiency in the use 
of the battery, so as to improve the reliability and stability of the vehicle's energy system. A typical battery management system should have the following functions:

(1) Monitoring and control function of the battery working state

The battery management system through the effective management of the battery installed in sensor signal provided the battery box. Real-time acquisition of each battery terminal voltage, temperature, charge (put) electric current, resistance and battery group the total voltage and other data; due to temperature changes in the other parameters have certain influence, so the general use of the temperature of the battery module as a control instruction signal, through the comparison of pre setting temperature value and the measured temperature value of, to decide whether the battery cooling.

(2) The detection function of the battery energy

Electrically driven robot in the operation process, the battery energy management system at any time on the robot's energy consumption were evaluated. Finally gives the battery inside the battery module of the remaining energy value, forecast battery remaining how much energy, calculated in the working state can how long to run, to prevent over discharge damage battery and battery is shortened service life.

(3) Monitoring and early warning control function

When the battery is in working state (charge and discharge performance of the battery module, security, performance monitoring, and the relevant parameters do record, memory, or for tips, warnings or parking instruction, stopping (charge) and the over-voltage, over-current, undervoltage, insulation etc. the warning and control functions. Remind the user to replace the battery, so as not to affect the reliability and stability of the battery and prolongs the battery life, reduce the use cost.

\section{Ensure The Normal Charging Function}

Battery management system (BMS) participate in real time vehicle monitoring, the working state of the battery monitoring, especially the technical state of each battery were analyzed, the detected data in the vehicle suspended, before charging "notice" charger, car and machine dialogue.[3] Tell the technological state of the charger, the battery working state and each battery, "battery" and "advanced" battery performance differences and backward. This charger should adopt what kind of charging mode to charge the battery, to reach to the battery is sufficient, the good performance of the battery can not overshoot, and poor performance of the battery can not put to ensure vehicle energy supplies. Ensure that the poor performance of the battery can not be placed in the discharge process, this should be the most important function of the battery management system.

\subsection{Vehicle Power Estimation Method}

Through the analysis of the vehicle energy consumption equipment, such as vehicle energy consumption estimation principle described below,Must be able to get the vehicle during the mission a time required to power and energy in the whole period of time consuming task. $[4,5]$

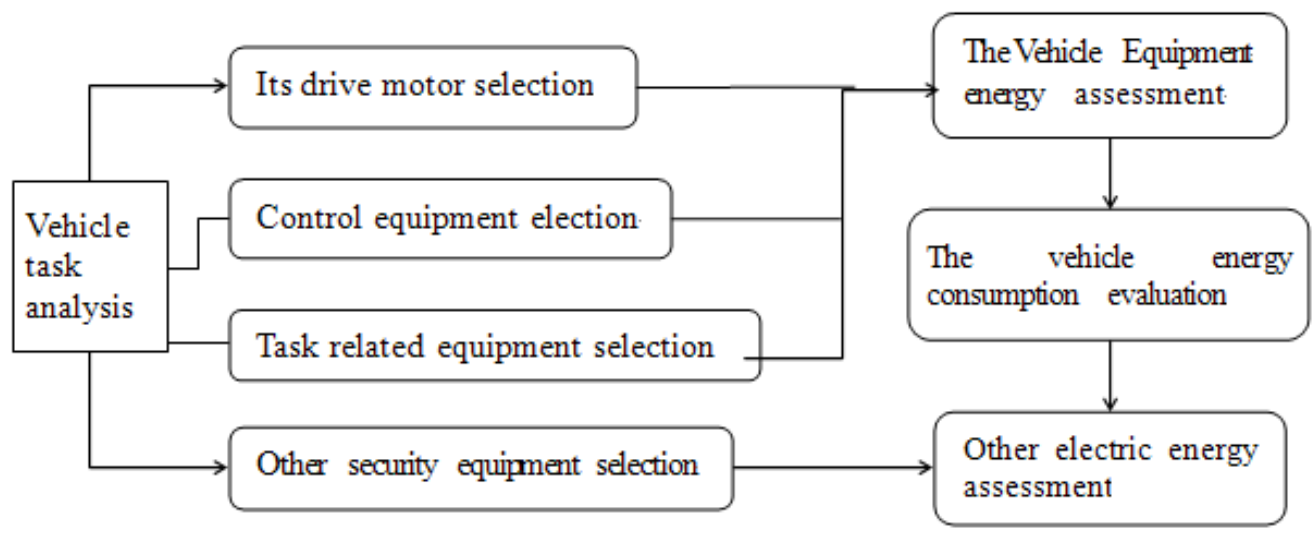

Fig. 1 Wheeled unmanned platform to estimate energy consumption 


\section{Hardware Circuit Design}

Including the central controller module with ARM microcomputer as the core, clock circuit, reset circuit, voltage reference circuit, JTAG circuit. The system hardware circuit principle diagram of 2 are as follows:

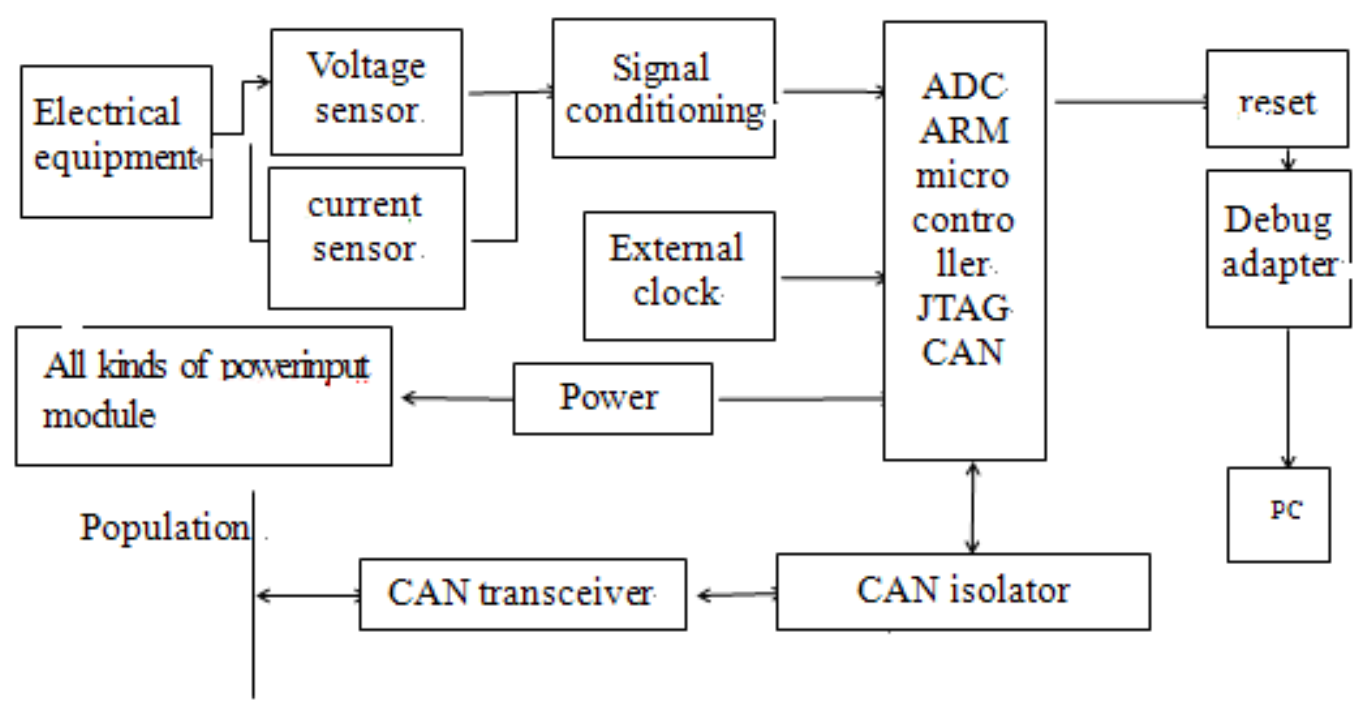

Fig2. Hardware design principle diagram

\section{Software Design}

Hardware to various functions with the corresponding software to achieve the preset, any microcontroller intelligent system function realization program is always a software decision. Compared to the versatility of the hardware design, software design is more flexible, and most of its design is for a particular object to achieve functional, therefore, according to the requirements of the system changing, the monitoring system of electric equipment in the program design follow the following principles:

The modular design method, the whole system to complete the function respectively writing and debugging, then debugging after the success of the various modules of the FBI to constitute the SCM software system. This design method is not only convenient procedure of connection and debugging, and helped to revise and transplantation.

The combination of hardware system, the rational allocation of system resources and efficient use of system resources.The actual operation ability of SCM based on the algorithm, ensure the operation speed and accuracy. [6]According to the requirements for electrical equipment monitoring module function, shows that the software system is needed to implement the function of real-time data acquisition and processing with the voltage and the current of the electric equipment, and through the CAN node communication module sends the data to the CAN bus. The program includes: initialization module, A/D sampling module and communication module from the CAN node, as shown in Fig.3 the relationship between modules:

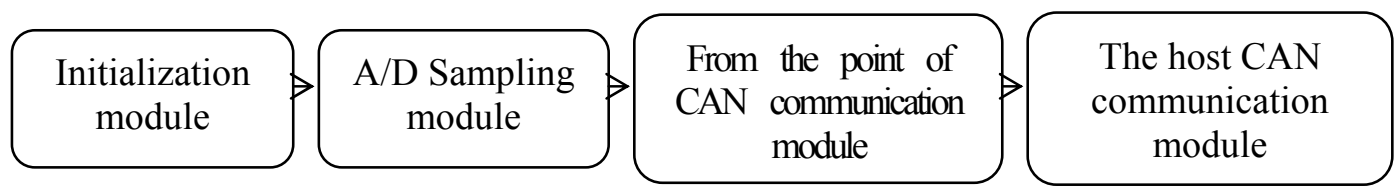

Fig.3 Module diagram 


\section{Technical difficulties}

An important function of electrically driven robot assisted battery current there is how much electricity, can work long, is in the operation of the robot must know the important parameters and is electrically driven robot energy management system should be completed. In general, the battery based on the principle of chemical reaction is a complex system, it depends on the properties of electrode material, electrolyte concentration, reaction temperature, state of charge, many factors such as time. Charge and discharge presents obvious non linear and dynamic resistance is very small, the reference model of multiple parameters, all is charge state 5OC parameters, and with the increase in the number of charge cycles, the parameters were changed. In an electrically driven robot to achieve energy management difficulty is how according to the acquisition of each battery voltage, temperature, charge and discharge current of the historical data, to establish a determined each battery remaining amount of energy more accurate mathematical model. Because of the above reasons, electric energy management system is very difficult in the development of robot assisted function, people are still making unremitting efforts.

\section{The Driving Energy Management Strategy For Optimal Torque Distribution}

Electric cars are generally single high power motor drive, but the work area click on the different efficiency characteristics are not the same, especially in the area of low efficiency and low torque speed zone is very low. Therefore, in a certain driving conditions, it is difficult to make it work by adjusting the motor running efficiency area. When the number of $\mathrm{N}>1$ motor, at a certain speed, the torque distribution of the motor, the motor can realize the working point of transfer to high efficiency, and improve the utilization rate of the vehicle battery energy.

If the car wheel speed are the same as in the linear good pavement to facilitate discussion, front and rear wheel torque distribution model is established based on the same side $1 / 2$ vehicle model.Let $\chi_{0}$ be a front wheel torque distribution coefficient,T requirements for $1 / 2$ vehicle model torque; $\mathrm{T}_{\text {req } 2}$ is assigned to the rear wheel. $x_{0}=\frac{\mathrm{T}_{\text {req } 1}}{\mathrm{~T}_{\text {req } 2}}$, So, $\mathrm{T}_{\text {req } 2}=\left(1-x_{0}\right) \mathrm{T}_{\text {req }}$.At a certain speed, front wheel hub motor speed $n$, the speed of peak driving torque, in order to ensure the safety of front and rear wheel motor, the motor output torque respectively meet the relationship

$$
\left\{\begin{array}{l}
\mathrm{T}_{\text {out } 1}=\min \left(\mathrm{T}_{\text {req1 } 1}, \mathrm{~T}_{n 1}\right) \\
\mathrm{T}_{\text {out } 2}=\min \left(\mathrm{T}_{\text {req2 } 2} / k, \mathrm{~T}_{k n 2}\right)
\end{array}\right.
$$

Type: $\mathrm{T}_{\text {out } 1}$ is the hub motor output torque; $\mathrm{T}_{\mathrm{n} 1}$ is the corresponding peak torque when the rotational speed of $\mathrm{N}$ hub motor; $\mathrm{T}$ is the peak torque of wheel motor speed too corresponding.

Thus, according to the distributed electric drive vehicle driving power transmission system to establish the topological structure of nonlinear optimization model

$$
\begin{aligned}
\min P=\frac{\mathrm{T}_{\text {out } 1}{ }^{n}}{9950 \eta_{m 1}}+\frac{\mathrm{T}_{\text {out } 2} k n}{9550 \eta_{m 2} \bullet \eta_{\text {red }}} \\
\operatorname{among}\left\{\begin{array}{l}
\mathrm{T}_{\text {req1 }}=x_{0} \mathrm{~T}_{\text {req }} \\
\mathrm{T}_{\text {req2 } 2}=\left(1-x_{0}\right) \mathrm{T}_{\text {req }} \\
\eta_{m 1}=\eta_{m 1}\left(n, \mathrm{~T}_{\text {out } 1}\right) \\
\mathrm{T}_{\text {out } 2}=\min \left(\mathrm{T}_{\text {req } 2} / k, \mathrm{~T}_{k n 2}\right) \\
\eta_{m 2}=\eta_{m 2}\left(k n, \mathrm{~T}_{\text {out } 2}\right) \\
\eta_{\text {red }}=\eta_{\text {red }}\left(k n, \mathrm{~T}_{\text {out } 2}\right)
\end{array}\right.
\end{aligned}
$$

In the formula:The $\eta_{\mathrm{m} 1}\left(n, \mathrm{~T}_{\text {out } 1}\right)$ is in the speed of $n$ wheel motor, When the torque for the efficiency of $\mathrm{T}_{\text {out } 1}$; The efficiency of $\eta_{\mathrm{m} 2}\left(k n, \mathrm{~T}_{\text {out } 2} / k\right) ; \eta_{\text {red }}\left(k n, \mathrm{~T}_{\text {out } 2} / k\right)$ is the speed reducer in the speed of $(k n)$; The torque $\left(\mathrm{T}_{\text {out } 2} / k\right)$ for the efficiency. 
By adjusting the front and rear drive torque distribution ratio between $x_{0}$ and to satisfy the constraint condition, make the front and the rear wheel drive the lowest energy consumption, which can be calculated in the speed and torque corresponding to the driving torque distribution coefficient map.

In low speed high torque the rear wheel side wheel machine, the proportion of relatively large, high-speed low torque the hub motor, the proportion of larger. According to the torque distribution coefficient figure is under ideal condition, the minimum energy consumption allocation scheme, in practice, vehicle at low speed start often used wheel rim motor work, high-speed low torque when the wheel motor work, consistent with the torque distribution coefficient of the trend, which also in theory the Shanghai real actual use of this distribution is its energy-saving benefits.

\section{1 brake torque distribution optimization}

With different driving conditions is in the braking condition, especially when the emergency brake, often needs braking torque motor braking torque exceeds the peak, therefore, need to consider the matching problem of electro-hydraulic brake. The regenerative braking energy recovery must take into account the battery power state, the vehicle safety and comfort. In order to avoid over charging, the battery is more than $90 \%$, will stop the regenerative braking energy recovery. In order to ensure the safety of automobile driving, the car is equipped with electro-hydraulic, ABS at low braking intensity, the motor brake braking energy recovery, as demand increases when the motor braking torque, braking torque can not meet the requirements of braking when is the introduction of mechanical hydraulic brake auxiliary brake in the motor, front and rear the speed output peak braking torque and demand braking torque between The difference is provided by the mechanical hydraulic brake.For the braking condition, a torque demand is negative, the regenerative braking power is also negative, compared with demand peak torque and motor braking torque, a regenerative braking power optimization model

$$
\begin{aligned}
& \operatorname{minP}=\frac{\mathrm{T}_{\mathrm{reg} 1} \bullet \bullet \bullet \eta_{m 1}}{9950}+\frac{\mathrm{T}_{\text {reg } 2} \bullet k \bullet n \bullet \eta_{m 2} \bullet \eta_{\text {red }}}{9550} \\
& \text { among }\left\{\begin{array}{l}
\mathrm{T}_{\text {req1 }}=x_{0} \mathrm{~T}_{\text {req }} \\
\mathrm{T}_{\text {req2 } 2}=\left(1-x_{0}\right) \mathrm{T}_{\text {req }} \\
\eta_{m 1}=\eta_{m 1}\left(n, \mathrm{~T}_{\text {out } 1}\right) \\
\mathrm{T}_{\text {reg1 }}=\max \left(\mathrm{T}_{\text {req1 } 1}, \mathrm{~T}_{n 1}\right) \\
\eta_{m 2}=\eta_{m 2}\left(k n, \mathrm{~T}_{\text {reg2 } 2}\right) \\
\eta_{\text {red }}=\eta_{\text {red }}\left(k n, \mathrm{~T}_{\text {reg } 2}\right) \\
\mathrm{T}_{\text {reg2 } 2}=\max \left(\mathrm{T}_{\text {req2 } 2} / k, \mathrm{~T}_{k n 2}\right)
\end{array}\right.
\end{aligned}
$$

In the formula: $T_{\text {reg1 }}$ said the wheel motor regenerative braking torque; $T_{\text {reg2 } 2}$ said the wheel motor regenerative braking torque; $\eta_{m 1}\left(n, \mathrm{~T}_{\text {reg1 }}\right)$ said the wheel motor speed is $n$, the efficiency of torque for $\mathrm{T}_{\text {reg1 }} ; \eta_{m 2}\left(k n, \mathrm{~T}_{\text {reg2 } 2}\right)$ said rim motor speed is $(k n), \mathrm{T}_{\text {reg2 }}$ torque efficiency; $\eta_{\text {red }}\left(k n, \mathrm{~T}_{\text {reg } 2}\right)$ is the reducer speed $(k n)$, torque efficiency of $\mathrm{T}_{\text {reg2 }}$. The torque distribution torque coefficient calculation corresponding to each speed torque, get the braking torque distribution coefficient diagram.

\section{2optimization results}

According to the control model is established, by efficiency optimization of torque distribution algorithm. The results showed that in the $25 \mathrm{~km} / \mathrm{h}$ and $45 \mathrm{~km} /$ two uniform condition hundred kilometer energy consumption respectively for $8.82 \mathrm{kw} / \mathrm{h} 11.40 \mathrm{kw} / \mathrm{h}$, and compared with fixed proportional allocation hundred kilometer energy consumption and energy saving respectively $6.95 \%$ and $3.21 \%$, as shown in table 1 . 
Table 1.One hundred kilometers consumption results

\begin{tabular}{cccc}
\hline working condition & $\begin{array}{c}\text { Fixed ratio } \\
\text { simulation }\end{array}$ & Fixed ratio test & $\begin{array}{c}\text { Optimization } \\
\text { simulation }\end{array}$ \\
I & 9.40 & 10.0 & 8.82 \\
II & 11.75 & 12.0 & 11.40 \\
\hline
\end{tabular}

\section{Conclusion}

The electric vehicle is one of the ways to solve the energy crisis and the increasingly serious environmental problems. Electric vehicle industrialization is an inevitable trend, but the industry technical standard is not unified, and clear energy management system of electric vehicle has the function of what and how to realize, will be large-scale promotion of electric car of the first step. And in this paper, the research of robot assisted four-wheel independent drive is with electric vehicle energy management platform, as a result of EMS is the core component of the battery and the vehicle, so the related technology easily extended to the relevant products, domestic and foreign enterprises in the energy management system do the very many outstanding research work, as there is a huge economic and social benefits of electric vehicles to provide more and more and more advanced equipment. Therefore, in the future to improve the energy management system, prospects for the development of electric vehicles will be more broad.

\section{Reference}

[1]. Powers W F, Nicastri P R. Automotive vehicle control challenges in the 21st century. Control Engineering Practice 2000, 8(6): 605-618

[2]. Maine Department of Environmental Protection Bureau of Air Quality. Zero Emission Vehicle Study.Technical Report, 2001

[3]. Wouk V. The hybrid are coming!. Proceedings of the 17th International Electric Vehicle Symposium,Montreal, Canada, 2000

[4]. Maggetto G, Mierlo J V. Electric vehicles, hybrid electric vehicles and fuel cell electric vehicles: state of the art and perspectives. Ann. Chim. Sci. Mat, 2001, 26(4): 9-26

[5]. Harding G G. Electric vehicles in the next millennium. Journal of Power Sources, 1999, 78(1-2):193-198

[6]. Sasaki S, Takaoka T, Matsui H, et al. Toyota's newly developed electric-gasoline engine Hybrid powertrain system. Proceedings of the 14th International Electric Vehicle Symposium, Orlando,Florida, USA, 1997 